\title{
Could immediate treatment change the management method of digital tendon musculotendinous junction avulsion?: a systematic review
}

\author{
Sam-Guk Park \\ Department of Orthopaedic Surgery, Yeungnam University Medical Center, Daegu, Korea
}

\begin{abstract}
Background: We conducted a systematic review of the literature to investigate the correlation between the interval to treatment and management of tendon avulsion ruptures in the musculotendinous junction (MTJ) of the forearm.

Methods: A thorough literatures search for studies of tendon avulsion injuries at the forearm was conducted using PubMed, MEDLINE, CINAHL, and Cochrane databases in accordance with the PRISMA guidelines. In total, five case series and 15 case reports accounting for 87 injured tendons involving 60 patients were selected for the analysis.

Results: Twenty-six patients had 44 tendon injuries associated with avulsion amputations, 31 patients had 38 tendon ruptures associated with closed avulsion injuries and three patients had five tendon ruptures associated with open avulsion injuries. Eighteen of the $49(37 \%)$ patients were immediately treated for tendon ruptures and one of the $32(3 \%)$ tendon ruptures treated via elective surgery was directly repaired. Additionally, 18 of the $30(60 \%)$ tendons were directly repaired and 12 of the $30(40 \%)$ tendons were transferred or side-to-side repaired in the immediately treated series. In contrast, one of the $28(4 \%)$ tendon ruptures were directly repaired and 27 of the $28(96 \%)$ tendons were transferred or side-to-side repaired in the electively treated series.
\end{abstract}

Conclusion: In managing digital tendon avulsions at the MTJ, an immediate treatment could provide an opportunity to repair the ruptured tendon directly to the muscle.

Keywords: Forearm; Tendons injuries; Avulsion; Emergency treatment

\section{INTRODUCTION}

Avulsion injuries of the tendons at their musculotendinous junction (MTJ) associated with traumatic digit amputations have been documented in previous studies [1-6]. However, tendon avulsion ruptures at the MTJ in the absence of digit amputations are rare; thus, the reports are not sufficient to

Received: August 18, 2017, Revised: October 15, 2017

Accepted: October 24, 2017

Corresponding Author: Sam-Guk Park, Department of Orthopaedic Surgery, Yeungnam University Medical Center, 170 Hyeonchung-ro, Nam-gu, Daegu 42415, Korea Tel: +82-53-620-3640, Fax: +82-53-628-4020

E-mail: radiorth@ynu.ac.kr obtain recommendations for proper treatment. Boyes et al. [7] investigated 80 subcutaneous ruptures of the flexor tendons and reported that avulsion at the tendon insertion accounted for $62.8 \%$ of the studied cases, whereas avulsions at the MTJ accounted for only 5.1\%. Although uncommon, tendon avulsion injuries at the MTJ could not be overlooked because treatment failures could result in an unrecognised compartment syndrome on a short-term basis when the tendons are avulsed from their muscle belly on the forearm or lumbricals on the hand, or in significant disability on a longterm basis [8]. Although methods of conservative management, such as splinting or wearing a brace, have occasionally been reported, most of the reported series involved cases of patients who underwent surgery or who had ruptures involv-

Copyright (C) 2017 Yeungnam University College of Medicine

This is an Open Access article distributed under the terms of the Creative Commons Attribution Non-Commercial License (http://creativecommons.org/licenses/by-nc/4.0/) which permits unrestricted non-commercial use, distribution, and reproduction in any medium, provided the original work is properly cited. 
ing the tendons [7,9-19]. Takami et al. [9] reported the largest series of ten patients who sustained closed avulsion ruptures at the MTJ of the forearm. Nine of the ten patients underwent exploratory procedures, and the eight completely ruptured tendons were managed with tendon transfer or sideto-side repair. None of the injuries were open, and no patients underwent immediate surgery. Theoretically, direct repair of injured tendons to the muscle could produce the best chance to achieve good function because the procedure merely entails the reconnection of two ends of a broken structure, with no additional dissection needed to expose or use other tendons [8]. However, the direct repair of such injuries is not usually feasible owing to the local muscle pathology, such as shredded, edematous muscle tissues and variable muscle retraction degrees $[15,20]$. In avulsion amputations, reattachment of the tendon to its muscle is the most favoured form of treatment when the digit was replanted [8]. Stevanovic et al. [4] reported the largest series of 17 patients who sustained traumatic amputations of the thumb with the tendons avulsed from the MTJ. Ten of the 17 patients underwent direct repair of the injured tendons to the muscle at the MTJ [4]. Directly repaired tendon avulsion ruptures at the MTJ in the absence of digit amputations have rarely been reported [10,11,19,21], and a portion of the cases were managed with immediate surgery. To investigate the correlation between the interval to treatment and management of tendon avulsion ruptures at the MTJ, cases were gathered through a systematic review of the literature [1-7,9-21] along with our own case.

\section{MATERIALS AND METHODS}

A thorough literature search of studies in any language on PubMed, MEDLINE, CINAHL, and Cochrane Databases from 1960 to 2015 was conducted. The search terms used in various combinations included "tendon", "injury", "avulsion", "rupture", "musculotendinous", "forearm”, “amputation", "repair", and "transfer". Two independent investigators conducted the search separately. Full text articles of relevant studies were obtained, followed by an extraction of data from each relevant article. Some papers written in non-English languages (Japanese and German) were included in the data after translation $[18,19,22]$. References of the selected articles were reviewed to avoid omitting relevant studies not included in the original search. Articles were selected in accordance with clear inclusion and exclusion criteria, and inconsistencies regarding the study inclusion were resolved by mutual agreement.

\section{Inclusion criteria}

All reported patients with tendon rupture at the MTJ of the forearm were included in this study. The study encompassed cases associated with traumatic digit amputations or closed traction injuries and any other mechanisms of the injury. Flexor or extensor tendons of any digit and amputation levels anywhere between the wrist and the fingertip were also included.

\section{Exclusion criteria}

(1) Ruptures at other levels of the tendon or muscle, (2) avulsions at other levels, (3) tendon ruptures caused by lacerations, (4) ruptures not caused by an acute trauma, (5) cases without proper treatment to restore finger function (revision amputation), (6) injuries associated with diseased tendons (e.g., rheumatoid arthritis), and (7) biomechanical studies were excluded from the study.

\section{Data extraction}

Data were collected for each tendon using a form that included patient demographics, cause of injury, injury mechanism (association with avulsion amputation or closed and open avulsion injuries), involved tendon, involved digit, level of bone amputation, interval to treatment, treatment method, duration of follow-up, and summary of reported outcomes (clinical outcomes and complications). These data were categorised in accordance with the involved tendon, associated injury, interval from trauma to treatment, and management method to identify the determinant factor for direct repairs of the injured tendons to the muscle.

\section{RESULTS}

A flow diagram outlining the systematic literature review process is shown in Fig. 1. A literature search together with cross-referencing yielded 143 articles. After the removal of duplicates, 132 articles remained. Title and abstract reviews 
excluded an additional 43 articles based on research objects irrelevant to our study. Of these 89 articles, 20 remained after the application of inclusion/exclusion criteria (one chart was from the author's result) [1-7,9-21]. In total, five case series and 15 case reports, accounting for 87 injured tendons invol-

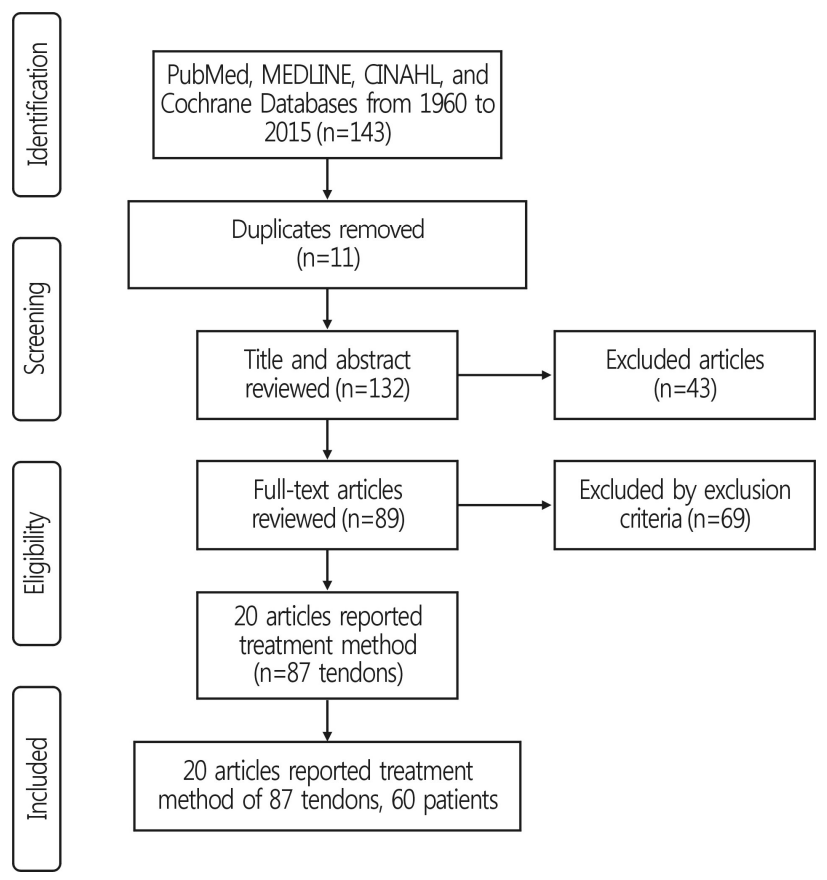

Fig. 1. PRISMA flow diagram.

Table 1. Patient demographics and details of the tendon injuries

\begin{tabular}{lc}
\hline Characteristic & Number \\
\hline Patients & 60 \\
Gender (male:female) & $53: 7$ \\
Mean age (yr) & 33.5 \\
Work injuries & 41 \\
Sports injuries & 10 \\
Accident & 9 \\
Injured tendons & 87 \\
Avulsion amputation & 44 \\
Closed avulsion & 38 \\
Open avulsion & 5 \\
Flexor pollicis longus & 25 \\
Flexor digitorum profundus & 2 \\
Flexor digitorum superficialis & 2 \\
Extensor pollicis longus & 26 \\
Extensor digitorum communis & 19 \\
Extensor indicis proprius & 11 \\
Extensor pollicis brevis & 1 \\
Extensor digiti minimi & 1 \\
\hline
\end{tabular}

ving 60 patients, were selected for the analysis. The general study and patient characteristics are summarised in Table 1. Most patients were men (53 men versus seven women), and their average age was 33.5 years (men, 33.8 years and women, 30.4 years; range, $2-67$ years). The dominant side was recorded in 34 of the 60 patients, with the dominant hand injured in 21 instances and the subordinate in 13 . Forty cases were work injuries, ten were sports injuries, and nine were injuries caused by accidental trauma. The diagnostic findings, treatment methodology, and clinical outcomes of each study are shown in Table 2. Twenty-six patients had 44 injured tendons associated with avulsion amputations, 31 patients had 38 tendon ruptures associated with closed avulsion injuries and three patients had five tendon ruptures associated with open avulsion injuries. Eighty-four (97\%) of the 87 tendon ruptures were treated surgically if the three partially ruptured tendons were subtracted. Fifteen of the $44(34 \%)$ tendon ruptures, secondary to avulsion amputations, and seven of the $43(16 \%)$ tendon ruptures, associated with avulsion injuries, were treated by direct repair (Fig. 2). Eighteen of the 49 (37\%) immediately treated tendon ruptures and one of the $32(3 \%)$ tendon ruptures treated via elective surgery were directly repaired (Table 2 ). If the three conservatively treated tendons (two that were partial injuries), six debrided tendons, and 12 tendons treated via tenodesis were excluded to compare direct repair with tendon transfer or side-to-side repair, then 18 of the $30(60 \%)$ tendons were directly repaired and 12 of the $30(40 \%)$ tendons were treated via tendon

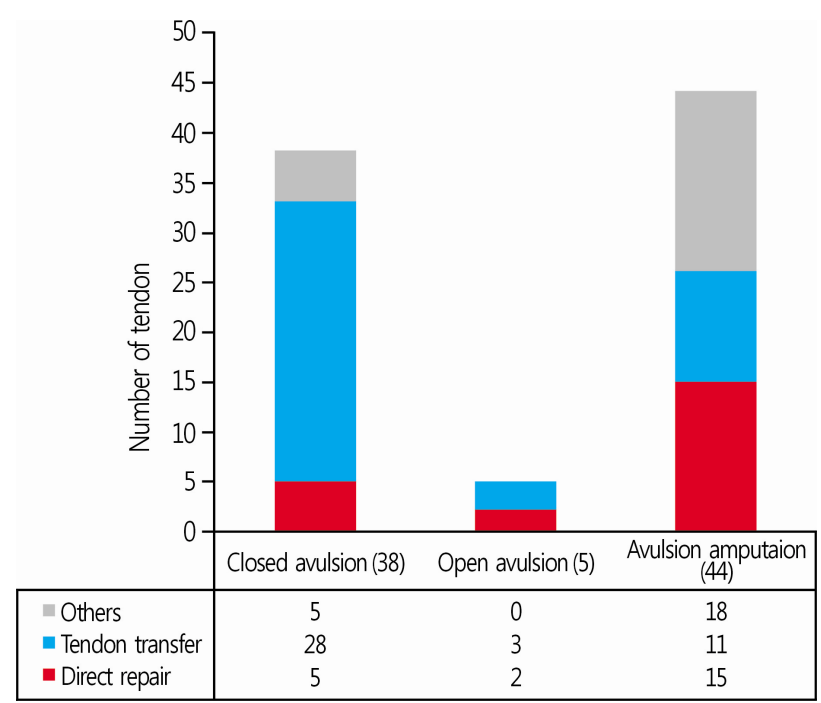

Fig. 2. Incidence of injury and treatment of the tendons. 
transfer or side-to-side repair in the immediately treated series (Fig. 3). Conversely, one of the 28 (4\%) tendon ruptures were treated via direct repair and 27 of the 28 (96\%) tendons were treated via tendon transfer or side-to-side repair in the electively delayed treated series (Table 2). The summarized data for each article are presented in Table 3.

\section{DISCUSSION}

When a longitudinal traction force is exerted in the opposite direction of the muscular contraction along the entire musculotendinous unit, the weakest sections would be on the insertion of the tendon, followed by the MTJ [7]. Consequently, when the insertion of the tendon was compressed during the injury, the tendon would be more likely to rupture at the MTJ. This mechanism is similar to that in the patient whose gloved hand was caught in revolving machinery. Subcutaneous avulsion rupture of apparently healthy tendons at the

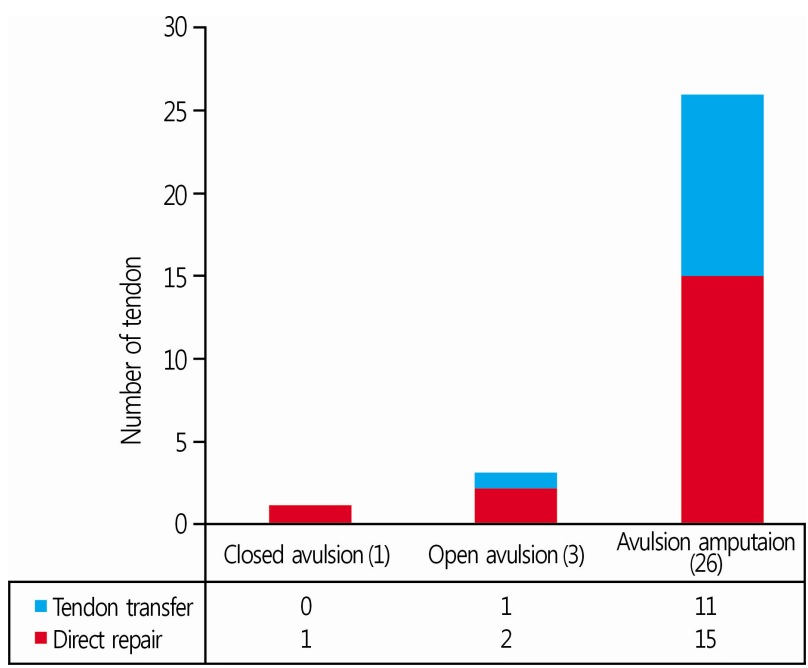

Fig. 3. Incidence of injury and treatment of the tendons, comparing direct repair with tendon transfer or side-to-side repair, excluding conservative treatment, debridement, and tenodesis.
MTJ occurs infrequently, and has rarely been documented in literature. Consequently, the definitive optimal recommendations were not standardised yet. According to our research, 40 of the 43 reported tendons completely ruptured, and 39 were treated via surgery. Most of the reported charts were not open injuries, and no patients underwent immediate surgery $[13,15,16,18-20]$. On the contrary, in the case of avulsion amputations and open avulsion injuries, most of the patients were treated immediately, and a substantial portion were treated via direct repair of the injured tendons to the muscle $[4,5,11,19]$. When tenodesis and debridement were excluded because they could not restore the gliding function of the tendon, $60 \%$ of the ruptured tendons were reattached to its muscle in the immediately treated cases. Conversely, 96\% of tendons were treated via tendon transfer or side-toside repair in the electively delayed treated series. Consequently, when managing digital tendon avulsions at the MTJ, the interval until treatment was considered to be an important factor in determining the treatment method.

Reattaching the tendon to the muscle has not been widely recognised as an available treatment option for subcutaneous avulsion injuries because it is not usually feasible because the muscle was shredded, edematous, or retracted $[15,20]$. Conversely, when treating a completely lacerated muscle disruption, physicians would attempt to treat them immediately and reattach the ruptured stumps to each other via sutures through the fascia overlying the muscle. In the majority of cases, sutures through the fascia might provide the strength to close the ruptured muscle. To the best of our knowledge, no studies have adequately demonstrated the relationship between different strengths of the muscle and pathological changes in the MTJ avulsion injuries over time. However, an experimental study of muscle injuries by Gallego et al. [24] showed that the ruptured muscle would be atrophied because it lost the

Table 2. Diagnostic findings and treatment methodology (number of injured tendons)

\begin{tabular}{|c|c|c|c|c|c|c|}
\hline & \multicolumn{5}{|c|}{ Avulsion $(n=43)$} & \multirow{3}{*}{$\begin{array}{c}\text { Amputation }(n=44) \\
\text { Open }(n=44) \\
\text { Immediate } \\
(n=44)\end{array}$} \\
\hline & \multicolumn{3}{|c|}{ Closed $(n=38)$} & \multicolumn{2}{|c|}{ Open $(n=5)$} & \\
\hline & $\begin{array}{c}\text { Immediate } \\
(n=2)\end{array}$ & $\begin{array}{c}\text { Delayed } \\
(\mathrm{n}=30)\end{array}$ & $\begin{array}{c}\text { Uncertain } \\
(n=6)\end{array}$ & $\begin{array}{c}\text { Immediate } \\
(\mathrm{n}=3)\end{array}$ & $\begin{array}{c}\text { Delayed } \\
(\mathrm{n}=2)\end{array}$ & \\
\hline Direct repair & 1 & 1 & 3 & 2 & 0 & 15 \\
\hline Tendon transfer/side-to-side & 0 & 25 & 3 & 1 & 2 & 11 \\
\hline Other methods & 1 & 4 & 0 & 0 & 0 & 18 \\
\hline
\end{tabular}

Other methods include conservative treatment, debridement, tenodesis, and plication. 
length-tension relationship, which is one of the main determisented an excessive dense scar formed at the site of the extennants of disuse atrophy. Moreover, Kääriäinen et al. [25] presive muscle injury. In some cases of human MTJ avulsion

Table 3. Range of follow-up times, summary of reported outcomes, and percentage of patients able to return to their preoperative activities (work or sports)

\begin{tabular}{|c|c|c|c|c|c|c|c|c|c|c|c|}
\hline Author & $\begin{array}{l}\text { No. of } \\
\text { cases }\end{array}$ & $\begin{array}{l}\text { No. of } \\
\text { tendons }\end{array}$ & Digit & $\begin{array}{c}\text { Involved } \\
\text { tendon }\end{array}$ & $\begin{array}{l}\text { Injury } \\
\text { type }\end{array}$ & $\begin{array}{l}\text { Level of } \\
\text { amputation }\end{array}$ & $\begin{array}{c}\text { Interval to } \\
\text { treatment }\end{array}$ & $\begin{array}{l}\text { Treatment } \\
\text { algorithm }\end{array}$ & $\begin{array}{l}\text { Range of } \\
\text { follow up }\end{array}$ & $\begin{array}{l}\text { Summary of } \\
\text { reported outcomes }\end{array}$ & $\begin{array}{l}\text { RTA } \\
(\%)\end{array}$ \\
\hline Culver [10] & 1 & 1 & D2 & FDS & Avulsion & & $2 \mathrm{wk}$ & Direct repair & 10 mon & $\begin{array}{l}\text { Lack } 5^{\circ} \text { of extension at } \\
\text { the PIPJ with flexion } \\
95^{\circ}\end{array}$ & 100 \\
\hline Givissis et al [11] & 1 & 1 & D1 & FPL & Avulsion & & Immediate & Direct repair & 30 mon & $\begin{array}{l}10^{\circ} \text { extension deficit, } \\
\text { full flexion, opposition }\end{array}$ & 100 \\
\hline Hoffman et al [1] & 1 & 2 & D5 & FDP, FDS & Amputation & PIPJ & Immediate & Debridement & & & \\
\hline Huemer et al [2] & 1 & 1 & D5 & FDP & Amputation & DIPJ & Immediate & Debridement & $7 \mathrm{wk}$ & $\begin{array}{l}50^{\circ} \text { of flexion in the } \\
\text { PIPJ, } 30^{\circ} \text { in the DIPJ }\end{array}$ & \\
\hline Kameyama et al [12] & 1 & 2 & D5 & $\begin{array}{l}\text { EDC, } \\
\text { EDM }\end{array}$ & Avulsion & & 4 mon & FCR transfer & $2 \mathrm{yr}$ & Full range of motion & 100 \\
\hline Komura et al [13] & 2 & 4 & D2 & $\begin{array}{l}\text { EIP, } \\
\text { EDC }\end{array}$ & Avulsion & & $6 \mathrm{~d}$ & $\begin{array}{l}\text { Debridement, side } \\
\text { to side, EDM } \\
\text { transfer, plication }\end{array}$ & 3-6 mon & $\begin{array}{l}5^{\circ} \text { of index MP exten- } \\
\text { sion lag, complete inde- } \\
\text { pendent index extension }\end{array}$ & 100 \\
\hline Milch et al [14] & 1 & 1 & D1 & EPL & Avulsion & & Uncertain & EIP transfer & 3 mon & & \\
\hline Mudgal et al [15] & 1 & 2 & $\begin{array}{l}\mathrm{D} 2,3 \\
4,5\end{array}$ & $\begin{array}{l}\text { EIP, } \\
\text { EDC }\end{array}$ & Avulsion & & $7 \mathrm{~d}$ & FCR transfer & 3 mon & $\begin{array}{l}\text { Good active MPJ } \\
\text { extension, } 60^{\circ} \text { of wrist } \\
\text { motion limitation }\end{array}$ & 100 \\
\hline Redden [16] & 1 & 1 & D1 & EPL & Avulsion & & $2 \mathrm{wk}$ & EIP transfer & 4 mon & $\begin{array}{l}\text { Independent thumb } \\
\text { extension without } \\
\text { index extension lag }\end{array}$ & 100 \\
\hline Stevanovic et al [4] & 1 & 28 & D1 & FPL, EPL & Amputation & $\begin{array}{l}\text { IPJ, PP, } \\
\text { MCP }\end{array}$ & Immediate & $\begin{array}{l}\text { Suture to muscle, } \\
\text { EIP transfer, PL } \\
\text { transfer, ECRL } \\
\text { transfer, 4th FDS } \\
\text { transfer, debridement }\end{array}$ & $3 \mathrm{yr}$ & $\begin{array}{l}\text { Pinching 60\%, grip } \\
70 \%\end{array}$ & \\
\hline Sunagawa et al [21] & 1 & 2 & D2 & $\begin{array}{l}\text { EIP, } \\
\text { EDC }\end{array}$ & Avulsion & & Uncertain & $\begin{array}{l}\text { Suture to muscle, } \\
\text { side to side }\end{array}$ & & & \\
\hline Takami et al [20] & 1 & 1 & D1 & FPL & Avulsion & & $2 \mathrm{wk}$ & 4th FDS transfer & $1 \mathrm{yr}$ & Full range of motion & 100 \\
\hline Takami et al [9] ${ }^{\text {a) }}$ & 10 & 13 & $\begin{array}{l}\mathrm{D} 1,2 \\
3,4\end{array}$ & $\begin{array}{l}\text { EPL, EIP, } \\
\text { EDC }\end{array}$ & Avulsion & & $2 \mathrm{~d}-2$ mon & $\begin{array}{l}\text { EIP transfer, EDM } \\
\text { transfer, ECRL } \\
\text { transfer, side to } \\
\text { side, splinting }\end{array}$ & $\begin{array}{l}12-36 \\
\text { mon }\end{array}$ & Full range of motion & 100 \\
\hline Vlastou et al [5] & 6 & 12 & D1 & FPL & Amputation & $\begin{array}{l}\text { DP, PP, } \\
\text { MCP }\end{array}$ & Immediate & Tenodesis & 3-10 mon & & \\
\hline Stuart et al [17] & 1 & 1 & D2 & EIP & Avulsion & & $3 \mathrm{~d}$ & Side to side & 3 mon & $\begin{array}{l}\text { Full range of motion } \\
\text { with full power }\end{array}$ & \\
\hline Tsuge et al [18] & 1 & 4 & $\begin{array}{l}\mathrm{D} 2,3 \\
4\end{array}$ & EDC & Avulsion & & $\begin{array}{l}4 w_{k}-2 \\
\text { mon }\end{array}$ & $\begin{array}{l}\text { ECRL transfer, EIP } \\
\text { transfer }\end{array}$ & & & \\
\hline Egawa et al [19] $]^{\text {b) }}$ & 7 & 7 & $\begin{array}{l}\mathrm{D} 1,2 \\
3\end{array}$ & $\begin{array}{l}\text { FPL, EPL, } \\
\text { EIP, EDC }\end{array}$ & Avulsion & & $\begin{array}{l}\text { Immediate- } \\
2 \text { mon }\end{array}$ & $\begin{array}{l}\text { Suture to muscle, } \\
\text { tendon transfer, } \\
\text { splinting }\end{array}$ & & & \\
\hline Doi [6] & 1 & 1 & D1 & FPL & Amputation & PP & Immediate & 2nd FDS transfer & 4 mon & $\begin{array}{l}\text { Do daily life without } \\
\text { difficulty }\end{array}$ & \\
\hline Towfigh [22] & 1 & 1 & D1 & EPL & Avulsion & & Uncertain & EIP transfer & & Full range of motion & \\
\hline Park SG & 1 & 2 & $\mathrm{D} 2$ & $\begin{array}{l}\text { EIP, } \\
\text { EDC }\end{array}$ & Avulsion & & Immediate & $\begin{array}{l}\text { Side to side, suture } \\
\text { to muscle }\end{array}$ & $1 \mathrm{yr}$ & $\begin{array}{l}\text { Full range of motion, } \\
15^{\circ} \text { lag at index MPJ } \\
\text { independent extension }\end{array}$ & 100 \\
\hline
\end{tabular}

RTA (\%), return to preoperative activities (percentage of patients in each group); D, digit (1 thumb, 2 index, 3 long, 4 ring, 5 small fingers); FDS, flexor digitorum superficialis; FPL, flexor pollicis longus; FDP flexor digitorum profundus; PIPJ proximal interphalangeal joint; DIPJ, distal interphalangeal joint; EDC, extensor digitorum communis; EDM, extensor digiti minimi; EIP, extensor indicis proprius; EPL, extensor pollicis longus; IPJ, interphalangeal joint; PP, proximal phalanx; MCP, metacarpophalangeal joint.

${ }^{a)}$ Delayed conservative treatment for 2 cases of partial tendon injury, ${ }^{\text {b) }}$ immediate conservative treatment for 1 case of EDC tendon injury. 
injuries, muscle function was not restored for 4 months $[12,18]$. Muscle atrophy would be more severe and scar formation would be more excessive because the tension was not restored for extended periods, which could result in the loss of strength to undergo suturing of the muscle.

Closed avulsion injuries have some important clinical features, including ecchymosis, tenderness, swelling around the injured MTJ, aggravation of pain with an affected digit motion, and decreased or absent motion of the involved digits. Radiological equipment, such as magnetic resonance imaging and ultrasound, enable early diagnosis and visualisation of the extent of injuries. If serious damage is suspected in the examination, an immediate exploration could provide the

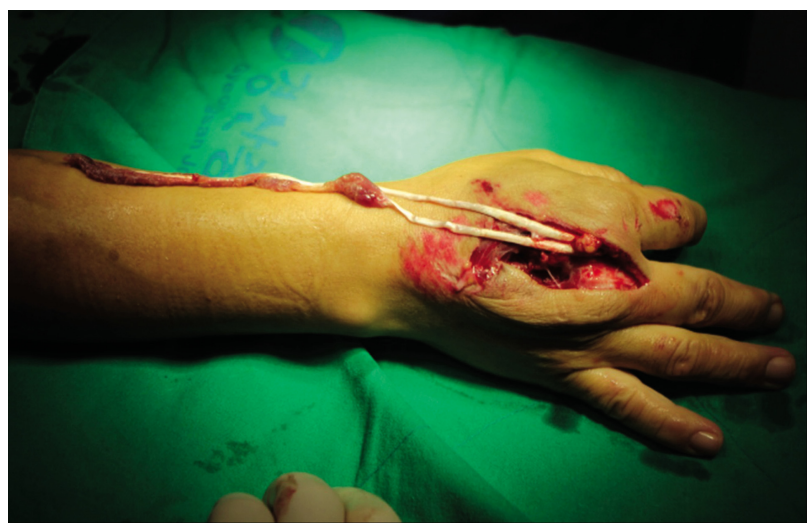

Fig. 4. Intraoperative photograph of the pulled-out extensor indicis proprius and extensor digitorum communis tendons of the index through an open wound at the right hand dorsum (the patient agreed to present the photograph in this paper).

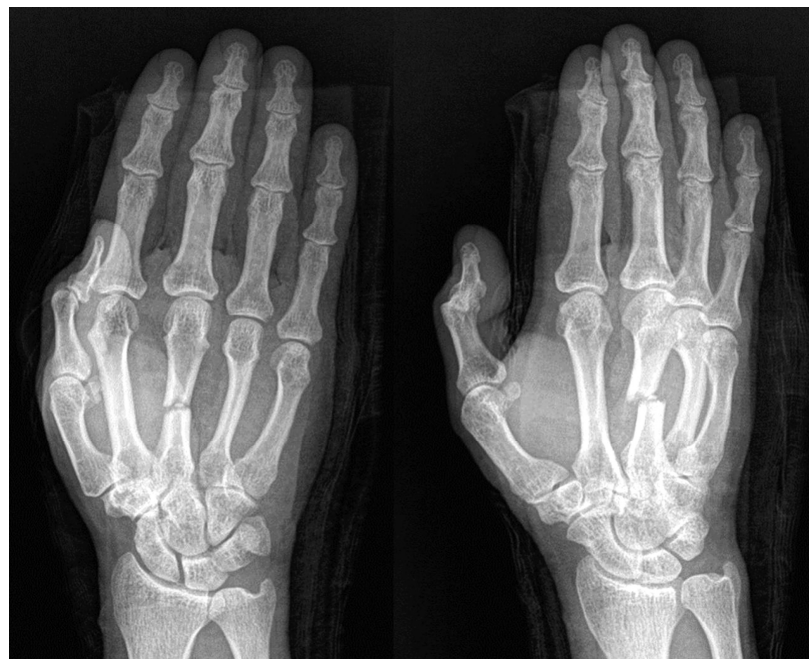

Fig. 5. Antero-posterior and oblique radiographs of the hand showing a third metacarpal bone shaft open fracture. chance to reconnect the two ends of a broken structure, with no additional dissection needed to expose and use other tendons [8].

The case of an open avulsion injury treated by the author that was included in the data is described below. A 46-yearold, right-hand-dominant man injured his hand when it was caught in revolving machinery. The extensor indicis proprius (EIP) and extensor digitorum communis (EDC) tendons of his index were pulled out through an 8-cm open wound at the right hand dorsum (Fig. 4). Plain radiographs suggested a third metacarpal bone shaft open fracture (Fig. 5). He was brought to the operating room within 5 hours of the initial injury. After induction of general anaesthesia, the open wound

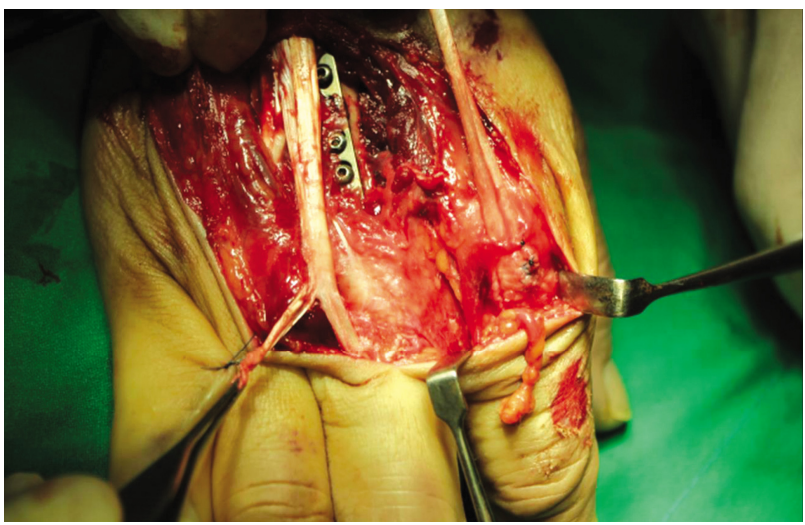

Fig. 6. Intraoperative photograph showing that the third metacarpal bone fracture was fixed with a mini-plate, the 2nd finger's sagittal band was repaired, and the 3rd finger's sagittal band was reconstructed with a partially torn third finger extensor tendon.

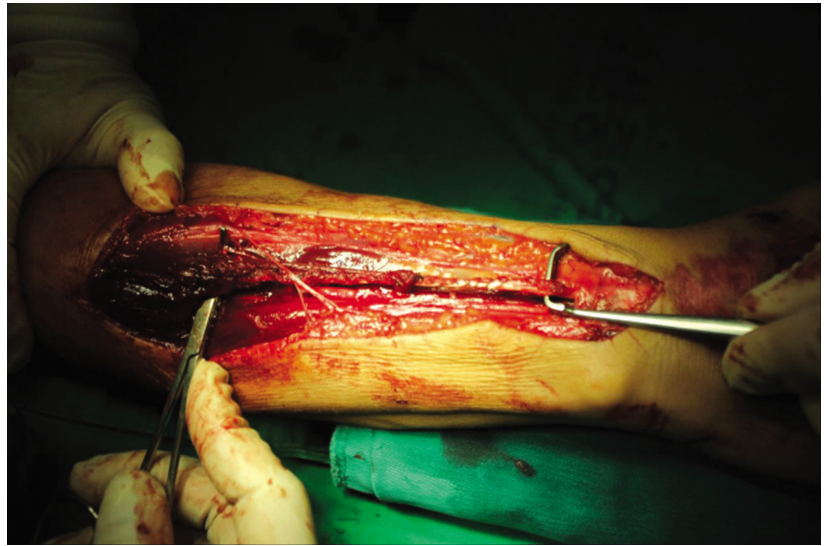

Fig. 7. Intraoperative photograph showing that the proximal end of the extensor indicis proprius tendon was sutured in an end-toside juncture to the index extensor digitorum communis tendon, and the tendon stump was sutured directly to the muscle with the augmented Becker's method. 


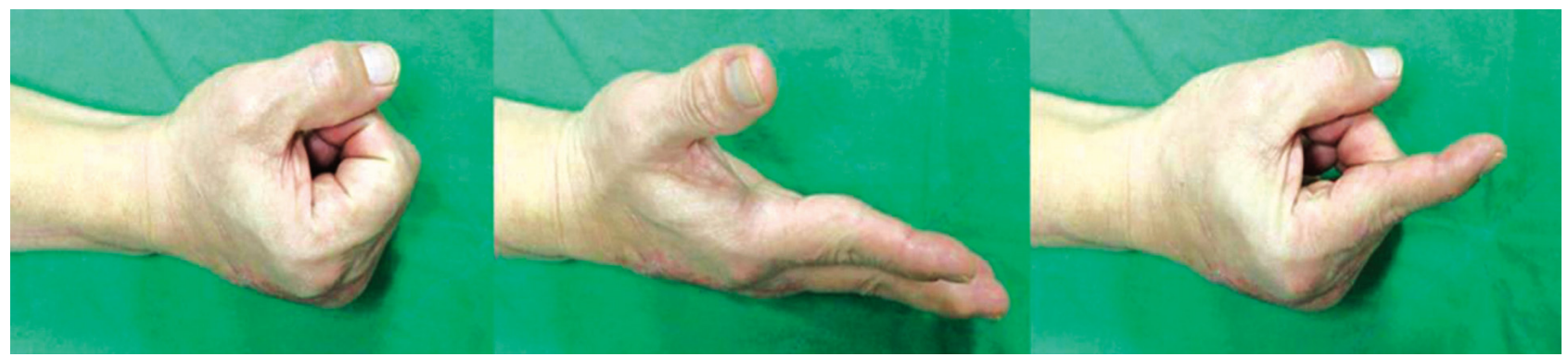

Fig. 8. Follow-up photographs 4 months after the surgery showing that the independent index metacarpophalangeal joint extension returned close to normal (full flexion, $10^{\circ}$ extension deficit), and all the fingers fully.

and muscle tissues attached at the avulsed tendons were debrided thoroughly, and the 3rd metacarpal bone fracture was fixed with a mini-plate (2.0 mm Modular Mini Fragment LCP, Synthes, West Chester, PA, USA) (Fig. 6). The sagittal band of the index finger ruptured, and the third finger's sagittal band rasped away. The proximal end of the EIP tendon was sutured in an end-to-side juncture to the index EDC tendon. The skin incision was extended to the proximal third of the forearm to access the detached muscle belly. The proximal muscle was edematous and retracted, and there was a small tendinous substance within the muscle. However, the muscle was still elastic enough to reach the avulsed tendon. The tendon stump was sutured directly to the muscle with the augmented Becker's method 24 using a Nylon 4-0 (Ethilon; Ethicon, Vienna, Austria). Length and tension were partially restored tightly (Fig. 7). A splint holding the wrist, index, and third finger in extension was applied for 6 weeks. Passive motion exercises as postoperative rehabilitation commenced 3 weeks postoperatively, and active motion exercises were initiated 6 weeks after surgery. The independent index metacarpophalangeal joint extension returned close to normal within 4 months (full flexion, $10^{\circ}$ extension deficit), and all fingers were fully extended (Fig. 8). Six months after surgery, the patient returned to his previous activities. The independent extension of the index finger could be an important factor for an active manual worker patient to return to his previous occupation.

This systematic review has limitations. The scarcity of data on this topic was an excuse for the emergence of this study, but ultimately was a unique weakness. High-level studies would be difficult to execute for this rare injury. Moreover, the quality of the studies could not be assessed since all 20 included studies consist only of case reports and case series.
Unfortunately, not one study describing the potential significance of the treatment of tendon avulsion ruptures in the MTJ of the forearm currently exists. Additionally, objective data concerning range of motion, strength, and satisfaction category were absent from many reports; thus, evaluating the effectiveness of direct repairs was not possible.

In the management of digital tendon avulsions at the MTJ, immediate exploration could be considered if serious damage, such as a complete rupture, is suspected in the physical examination and radiologic evaluation because it can provide an opportunity to repair the ruptured tendon directly to the muscle, with no additional dissection needed to expose and use other tendons.

\section{ACKNOWLEDGEMENT}

No funds were received in support of this work. No benefits in any form have been or will be received from a commercial party related directly or indirectly to the subject of this manuscript.

\section{CONFLICT OF INTEREST}

No potential conflict of interest relevant to this article was reported.

\section{ORCID}

Sam-Guk Park, https://orcid.org/0000-0002-1135-5179

\section{REFERENCES}

1. Hoffman S, Simon BE, Nachamie B. Unusual flexor tendon 
ruptures in the hand. Arch Surg 1968;96:259-62.

2. Huemer GM, Dunst KM. Images in clinical medicine. Finger avulsion with pulled-out flexor tendon. N Engl J Med 2005; 352:e5.

3. Hussain SA. Traumatic amputation of the finger with complete avulsion of flexor profundus tendon. J Trauma 1977; 17:241-2.

4. Stevanovic MV, Vucetic C, Bumbasirevic M, Vuckovic C. Avulsion injuries of the thumb. Plast Reconstr Surg 1991; 87:1099-104.

5. Vlastou C, Earle AS. Avulsion injuries of the thumb. J Hand Surg Am 1986;11:51-6.

6. Doi K. Replantation of an avulsed thumb, with application of a neuro-vascular pedicle. Hand 1976;8:258-60.

7. Boyes $\mathrm{JH}$, wilson $\mathrm{JN}$, smith JW. Flexor-tendon ruptures in the forearm and hand. J Bone Joint Surg Am 1960;42-A: 637-46.

8. Collins J, Ishihara Y, Thoma A. Management of digital tendon avulsion at the musculotendinous junction of the forearm: a systematic review. Hand (N Y) 2012;7:134-42.

9. Takami H, Takahashi S, Ando M, Suzuki K. Traumatic rupture of the extensor tendons at the musculotendinous junction. J Hand Surg Am 1995;20:474-7.

10. Culver JE Jr. Flexor digitorum superficialis rupture: a case report. Bull Hosp Joint Dis 1976;37:30-3.

11. Givissis P, Karataglis D, Christodoulou A, Terzidis I, Pournaras J. Open traumatic avulsion of the flexor pollicis longus tendon from the musculotendinous area: a case report. J Hand Surg Am 2005;30:850-3.

12. Kameyama M, Shiraishi T. Traumatic rupture of the extensor digitorum communis and extensor digiti minimi at the musculotendinous junction associated with volar dislocation of the distal radioulnar joint--a case report. Hand Surg 2000;5: 165-8.

13. Komura S, Yokoi T, Nonomura H. Traumatic closed index extensor tendon rupture at the musclotendinous junction: a report of two cases. Hand (N Y) 2011;6:90-2.
14. Milch E, Epstein MD. Traumatic rupture of the extensor pollicis longus tendon. Ann Plast Surg 1987;19:460-2.

15. Mudgal CS, Mudgal S. Closed traumatic rupture of the extensor digitorum communis and extensor indicis proprius at the musculo-tendinous junction. J Hand Surg Eur Vol 2007; 32:675-6.

16. Redden JF. Closed acute traumatic rupture of extensor pollicis longus tendon-a report of two cases. Hand 1976;8:173-5.

17. Stuart PR, Briggs PJ. Closed extensor tendon rupture and distal radial fracture with use of a gymnast's wrist support. Br J Sports Med 1993;27:92-3.

18. Tsuge K, Iwasaki H, Baba I, Hiramatsu K. Experiences and observations on cases of tendon tear of the fingers. Seikei Geka 1969;20:659-64.

19. Egawa J, Doi T, Tajima T, Okayama T. Subcutaneous rupture of the tendon and muscle. Seikei Geka 1969;20:1442-4.

20. Takami H, Takahashi S, Ando M, Kabata K. Rupture of the flexor pollicis longus tendon at the musculotendinous junction in a bowler. Arch Orthop Trauma Surg 1998;117:277-8.

21. Sunagawa T, Harada A, Ochi M. Traumatic closed index extensor tendon rupture: a case report. J Hand Surg Eur Vol 2009;34:554-5.

22. Towfigh $\mathrm{H}$. Muscular rupture of the extensor pollicis longus. Handchir Mikrochir Plast Chir 1984;16:234-5.

23. Lee SK, Dubey A, Kim BH, Zingman A, Landa J, Paksima N. A biomechanical study of extensor tendon repair methods: introduction to the running-interlocking horizontal mattress extensor tendon repair technique. J Hand Surg Am 2010;35: 19-23.

24. Gallego R, Huizar P, Kudo N, Kuno M. Disparity of motoneurone and muscle differentiation following spinal transection in the kitten. J Physiol 1978;281:253-65.

25. Kääriäinen $M$, Kääriäinen J, Järvinen TL, Sievänen $H$, Kalimo $\mathrm{H}$, Järvinen $\mathrm{M}$. Correlation between biomechanical and structural changes during the regeneration of skeletal muscle after laceration injury. J Orthop Res 1998;16:197-206. 